Article

\title{
Evaluation of the Optimal Connection of Power Transformers in the Substations of a Hospital
}

\author{
Carlos Javier Renedo * (D), Agustín Santisteban, Félix Ortiz ${ }^{(\mathbb{D}}$, Cristian Olmo and Alfredo Ortiz \\ Electrical and Energy Engineering Department, University of Cantabria, 39005 Santander, Spain; \\ agustin.santisteban@unican.es (A.S.); felix.ortiz@unican.es (F.O.); cristian.olmo@unican.es (C.O.); \\ ortizfa@unican.es (A.O.) \\ * Correspondence: renedoc@unican.es; Tel.: +34-942-20-13-74
}

Received: 2 January 2018; Accepted: 6 February 2018; Published: 11 February 2018

\begin{abstract}
Transformers are installed in power distribution systems to perform changes in supply voltage. Large consumers often have several transformers installed in parallel to ensure continuity of supply in the event of failure. These machines can achieve very high efficiency, but their efficiency is not constant since it depends on the power demanded at each time. Therefore, the level of efficiency that correspond to the operation of a specific transformer depends on two factors: machine technical characteristics and electrical load. In this work, the authors have proposed a methodology which shows the optimal number of transformers to be connected at each period in the substations of a large Spanish hospital, in order to achieve the maximum seasonal efficiency of these machines. The results of the energy saving are determined with respect to the current situation, in which all the transformers are permanently connected. On the other hand, the European Union has established a new regulation that sets the minimum energy efficiency requirements for new power transformers. This efficiency improvement is proposed to be applied gradually in two stages, a first limit came into force in 2015, while a more restrictive approach will appear in the year 2021. This work has also studied the potential energy savings that would occur when the substations of the hospital have more efficient transformers complying with the new European Regulation 548/2014.
\end{abstract}

Keywords: power transformer; efficiency; seasonal efficiency

\section{Introduction}

Nowadays, in the developed world, electricity is one of the main energy carriers; in Spain almost $25 \%$ of the energy consumption is carried out in the form of electricity, Table 1 [1]. Therefore, measures to improve the efficiency of the generation, distribution and consumption of this energy are essential aspects of a policy that wants to guarantee safe, affordable and sustainable energy.

Table 1. Annual evolution of energy consumption in Spain (Unit: thousands of tonnes of oil equivalent) Source: IDAE [1].

\begin{tabular}{ccccccc}
\hline Energy Source & $\mathbf{2 0 1 0}$ & $\mathbf{2 0 1 1}$ & $\mathbf{2 0 1 2}$ & $\mathbf{2 0 1 3}$ & $\mathbf{2 0 1 4}$ & $\mathbf{2 0 1 5}$ \\
\hline Coal & 1603 & 1915 & 1507 & 1752 & 1546 & 1515 \\
Petroleum products & 53,171 & 50,119 & 45,543 & 43,603 & 42,413 & 40,323 \\
Natural gas & 14,848 & 14,486 & 14,987 & 15,254 & 14,695 & 13,218 \\
Electricity & 21,053 & 20,942 & 20,661 & 19,953 & 19,576 & 19,955 \\
Renewables & 5367 & 5815 & 6297 & 5293 & 5294 & 5290 \\
Total & 96,042 & 93,277 & 88,995 & 85,855 & 83,525 & 80,303 \\
\hline
\end{tabular}

The electrical energy must be transported from the power stations, where it is generated, to the points of consumption, which can be separated by long distances. In this way, the main component of 
the transmission and distribution networks are the power lines. Table 2 shows data from the Spanish Transmission System Operator (REE) [2]. The distribution of electricity has associated energy losses, which are proportional to the square of the electric current. In order to transport a given power with lower losses, the voltage level in the power lines should be increased. Therefore, the search for energy efficiency provoked power transformers to appear in power grids. The objective of using these machines is to minimize the losses in the transmission and distribution of electricity, and they do it by increasing the voltage in different stages. The optimization of distribution transformers is one of the key points for reducing network losses [3], which have not only technical but also economic and environmental implications [4].

Table 2. Evolution of the Spanish transmission and transformation power system [2].

\begin{tabular}{cccccccc}
\hline Network Size & $\mathbf{2 0 1 0}$ & $\mathbf{2 0 1 1}$ & $\mathbf{2 0 1 2}$ & $\mathbf{2 0 1 3}$ & $\mathbf{2 0 1 4}$ & $\mathbf{2 0 1 5}$ & $\mathbf{2 0 1 6}$ \\
\hline Km of circuit (at 400 kV) & 18,792 & 19,671 & 20,109 & 20,639 & 21,094 & 21,179 & 21,620 \\
Km of circuit $(\leq 220 \mathrm{kV}) \times$ & 17,401 & 18,001 & 18,370 & 18,643 & 18,762 & 18,924 & 19,026 \\
$\quad$ excluded isles & 66,596 & 68,996 & 74,596 & 76,871 & 79,871 & 84,794 & 85,144 \\
\hline Transformation capacity (MVA)
\end{tabular}

On the other hand, the use of electricity is safer in low voltage than in high voltage. Thus, it is necessary to install transformers near the consumers, for reducing the voltage available in domestic, commercial and industrial areas. In many parts of the world, including Europe, China and Africa, the final consumer voltage is $230 / 400 \mathrm{~V}$; while in North America it is $120 / 240 \mathrm{~V}$. Transformers operated by distribution companies are responsible for supplying $70 \%$ of electricity to end-users at low voltage [5]. The rest of the distribution transformers in this range of voltages are owned by large commercial customers and industries. In this sense, it is customary that large consumers of electricity, typically industrial or commercial, have a substation for reducing the value of the voltage supplied by the distribution company to the voltage of end use. Several transformers in parallel are usually installed in these substations, whose sum of powers is higher than the customer demands. This allows carrying out maintenance operations and ensures continuity of supply in case of failure of a transformer.

Power transformers are electrical machines that achieve very high nominal efficiencies, above 0.99 . However, the interest of reducing losses in power transformers is an issue that, although old, continues to be discussed today, as demonstrated by the recent publication of the IEEE standard [6]. In this document, a detailed analysis is carried out, establishing a method for determining the value of the electric power needed to supply the losses of a transformer.

There are many works that have carried out a study on technical improvements of transformers. In [7], a review of the papers that try to reduce losses by improving different constructive aspects, is carried out. This work classified the transformer loss problem into three main groups: (a) tank losses due to high-current bushings; (b) losses in transformer core joints; and (c) stray losses in the transformer tank.

There are several ways to reduce losses in power transformers. For instance, three different methodologies are considered in [8]: (a) using aluminum electromagnetic shields; (b) reducing the dielectric losses and (c) the impact of the joints design parameters of the wound core.

It is known by transformer manufacturers that the efficiency of large power transformers depends on load losses and no-load losses. The load losses depend on the current and the resistance of the electrical circuit, while the no-load losses are caused by the eddy current and hysteresis occurring at the core material of the transformer, and therefore these can be attributed to the magnetic properties of the deployed grain-oriented electrical steel material. This way, one of the most used methodologies to reduce losses in power transformers is to study the materials used. This has been the object of study for a long time; for example, in [9] the authors conducted a study of the characteristics of different magnetic materials for their application in electrical devices. 
In this way, there are several recent works that studied this aspect. In [10], the authors offered the results of the test performed on different power transformers. They concluded that the losses varied $1.5 \%$ between the one that used better and worse materials. In [11], a study based on a 3D model that considers different electrical steels is presented. The results showed that core losses can be reduced up to $30 \%$; this reduction also implies that lower temperatures are reached in the transformer oil. Their results were validated with laboratory tests. Finally, the authors recommend that in the case that different materials are combined for the construction of the core, the low-loss steel is used in the inner core and the high-loss steel is used in the outer core. This contributed to avoiding an increase in power losses and in temperature in the transformers core.

In a more recent work [12], the results and analysis of 3D simulations carried out to study the losses in the core of power transformers have been presented. The authors studied several electrical steels of different qualities, and their combination for the manufacture of the core. They showed data on the variation of the core manufacturing cost, and affirmed that for the construction of a transformer with certain losses, the manufacturing cost can be reduced when different materials are combined.

There are works that follow other research lines in order to improve the efficiency of power transformers. For example, in [13] the authors proposed reducing losses in distribution systems by using shunt capacitor banks coordinated with transformers. With them, they tried to minimize the reactive power and to increase the efficiency of the system by decreasing the losses generated in the power transformers. These losses can reach up to $55 \%$ of transmission and distribution losses. In this work, the authors studied the reduction of load losses by decreasing the current passing through its windings. By installing capacitor banks, a portion of the reactive power demand can be directly compensated, thereby reducing the current.

However, the efficiency of these machines is not constant, but it depends on the load or demand of electricity at each moment. There is an optimum load at which the transformer works at maximum efficiency or minimum losses, and as the load goes up or down relative to that value, the efficiency decreases. Therefore, the fact that a transformer reaches a high efficiency depends both on its nominal efficiency and that it works close to its optimum load. Following this concept, another research line was looking for the optimization of transformer operation [14,15].

Finally, it can be stated that the losses produced in the transformers have economic implications. In [16], the authors analyze equations for the determination of the cost of the electric energy loss in power transformers.

In Spain, approximately 30\% of the national energy consumption takes place in buildings [1]. A very significant part of this energy is demanded in the form of electric power. One example of these typical consumptions correspond to large complexes of permanent and predictable occupation, such as commercial centers, large airports, railway stations or hospitals. The analysis presented in this article matches the previous characteristics. The electrical demand is variable according to the time of the day and the period of the year, and it is also predictable. On the other hand, these consumers usually have substations where several transformers are installed in parallel.

In this work, the authors have studied the optimal number of transformers that should be connected in the substations of a hospital complex. The objective is to achieve the maximum seasonal efficiency of these electrical machines. The energy saving obtained with respect to the current operation in the hospital has been determined. Nowadays, the electrical energy is supplied by means of a fixed number of power transformers. As the control of the number of connected transformers that maximizes the efficiency implies a high number of switching maneuvers, another alternative has been studied. The number of connected transformers is selected at the beginning of each working period in the hospital.

The high efficiency of transformers do not produce important percentage in energy savings. However, the energy managed by these machines is very large, and any small percentage improvement will produce great energy savings. Thus, the European Union has promoted a new regulation that establishes the minimum energy efficiency requirements for new power transformers. This efficiency 
improvement is proposed to be applied gradually in two stages, establishing a first limit in 2015 and a second more restrictive in the year 2021. In this way, this study has also considered the energy savings that would occur with the control techniques proposed, taking into account more efficient transformers that comply with the new European regulation.

Only one study has been found in the literature that considers this work methodology [14], however, it is carried out in substations with two transformers. In our work, we took into account four parallel transformers, the consumption in different periods of time, making an hourly and seasonal prediction of the number of transformers that should be connected in order to reduce losses.

Additionally, the connection or disconnection maneuvers of transformers at the beginning of each work shift has been studied. This increases the lifespan of these machines.

Moreover, a new analysis considering the new European regulation on transformers efficiency has been performed. This allows us to see the effect that would occur with the use of more efficient transformers.

The paper is organized as follows. Section 2 discusses the materials and methods and it is organized in three subsections: Section 2.1 studies the losses and efficiency associated with power transformers, Section 2.2 presents the Europeans Regulations on Transformer energy efficiency, and Section 2.3 describes the studied case. Section 3 presents the results. Finally, some conclusions are drawn in Section 4.

\section{Materials and Methods}

This section presents the materials and methodology followed in this work.

\subsection{Efficiency and Losses of Power Transformers}

Large power transformers are machines with nominal efficiencies greater than $99 \%$, defining their efficiency $\eta$, as the ratio between output power, $P_{2}$ and input power, $P_{1}$, Equation (1) [17].

$$
\eta=\frac{P_{2}}{P_{1}}
$$

The output power can be obtained from the output apparent power, $S_{2}$ (the product of voltage and current absorbed by the load), and the load power factor, $\cos \varphi_{2}\left(\varphi_{2}\right.$ being the phase difference between the current and voltage waveforms). However, a transformer does not have to work at $100 \%$ load, in fact, managers of the transformer fleets prefer not to reach that level of demand. The load index of a transformer, $C$, is defined as the relation between the apparent power supplied, $S_{2}$, and the nominal apparent power, $S_{n}$. In this way, the output power can be expressed in function of the load index, Equation (2).

$$
P_{2}=U_{2} \times I_{2} \times \cos \varphi_{2}=S_{2} \times \cos \varphi_{2}=\left|C=\frac{S_{2}}{S_{n}}\right|=C \times S_{n} \times \cos \varphi_{2}
$$

Due to the internal losses associated with transformers operation, the efficiency is always lower than 1 . Therefore, output power is always lower than input power. Thus, the difference between input power, $P_{1}$, and the output power, $P_{2}$, is the power losses, $P_{L}$. These power losses are composed of: no-load losses, $P_{0}$, and load losses, $P_{k}$. The no-load losses are associated with the magnetization of the transformer magnetic circuit; these are known as iron losses and their value is constant. The load losses are associated with the losses in conductors, its value depends on the specific current flow that is fixed by the load index, $C$, and the losses produced in the short-circuit test, $P_{s c}$, Equation (3). In this way, power losses can be expressed according to Equation (4).

$$
\begin{gathered}
P_{k}=C^{2} \times P_{s c} \\
P_{L}=P_{1}-P_{2}=P_{0}+P_{k}=P_{0}+C^{2} \times P_{s c}
\end{gathered}
$$


Therefore, the efficiency of a transformer can be expressed as a function of the load index, Equation (5).

$$
\eta=\frac{P_{1}-P_{L}}{P_{1}}=1-\frac{P_{L}}{P_{2}+P_{L}}=1-\frac{\left(P_{0}+P_{k}\right)}{\left(C \times S_{n} \times \cos \varphi_{2}\right)+\left(P_{0}+P_{k}\right)}=1-\frac{P_{0}+C^{2} \times P_{s c}}{C \times S_{n} \times \cos \varphi_{2}+P_{0}+C^{2} \times P_{s c}}
$$

All values in the previous equation are constants and are associated to each transformer design, the only exception is the load index. Thus, the derivative of this expression could be used in order to find the maximum efficiency that a transformer could reach, $\eta_{\max }$. The load index associated with the maximum efficiency is known as optimum, $C_{\text {opt }}$. In this case, the no-load losses are equal to the load losses. The variation of the load makes it impossible to work under a constant load index. However, most managers of power transformers fleets try to operate their machines at a load rate close to the $C_{\text {opt }}$. This way, the optimum load index and the maximum efficiency can be easily determined, Equation (6).

$$
\text { If } P_{0}=P_{k} \Rightarrow\left\{\begin{aligned}
C=C_{o p t}\left|P_{0}=P_{k}=C_{o p t}^{2} \times P_{s c}\right| & =\sqrt{P_{0} / P_{s c}} \\
\eta=\eta_{\max }=1-\frac{P_{0}+\left(P_{0} / P_{s c}\right) \times P_{s c}}{\sqrt{\left(P_{0} / P_{s c}\right)} \times S_{n} \times \cos \varphi_{2}+P_{0}+\left(P_{0} / P_{s c}\right) \times P_{s c}} & =1-\frac{2 \times P_{0}}{\sqrt{\left(P_{0} / P_{s c}\right)} \times S_{n} \times \operatorname{co} \varphi_{2}+2 \times P_{0}}
\end{aligned}\right.
$$

In most practical situations, the reactive power of the electric power transformers is usually compensated by the addition of capacitor banks, and therefore, the $\cos \phi_{2}$ of the installation is 1 . This is the case of the installation studied in this work.

\subsection{European Regulation}

The European Commission is promoting regulations that increase the efficiency of equipment and installations by reducing energy consumption. One of these directives considers the efficiency of the new power transformers to be installed in Europe [18]. This regulation establishes two temporary limits, Tier 1 for 1 July 2015 and Tier 2 for 1 July 2021. These limits set the maximum losses associated with the operation of transformers under load and under no load. The losses are fixed according to: type of construction, voltage and apparent power. The Tier 1 was a first objective for transformers efficiency that the European authorities considered achievable in the short term. The Tier 2 is the real goal to achieve and a period of six years was established so that the manufacturers of these machines could adapt their designs. Table 3 shows the limits for dry transformers of $1 \mathrm{MVA}, 24 \mathrm{kV}$ primary voltage and $1.1 \mathrm{kV}$ secondary voltage, which are those studied in this work.

Table 3. Limits Tier 1 and Tier 2 for dry transformers (1 MVA, $\left.V_{1} \leq 24 \mathrm{kV}, V_{2} \leq 1.1 \mathrm{kV}\right)$ [18].

\begin{tabular}{cccc}
\hline \multicolumn{2}{c}{ Tier 1/1 July 2015 } & \multicolumn{2}{c}{ Tier 2/1 July 2021 } \\
\hline Max Load Losses & Max no-Load Losses & Max Load Losses & Max no-Load Losses \\
$P_{\mathrm{k}}(\mathrm{W})$ & $P_{0}(\mathrm{~W})$ & $P_{\mathrm{k}}(\mathrm{W})$ & $P_{0}(\mathrm{~W})$ \\
\hline 9000 & 1550 & 9000 & 1395 \\
\hline
\end{tabular}

\subsection{Description of the Installation}

The substation studied is installed in a hospital complex of $10,000 \mathrm{~m}^{2}$. This kind of buildings are large consumers of energy, and there is a worldwide interest in decreasing their demand [19]. The hospital studied consists of 20 buildings with different sizes and orientations. Most of the space is intended for patient accommodation in rooms, but there are also external consultations, analysis and diagnostic services, operating and emergency rooms.

The hospital has a substation with the main connection, from which split two distribution rings that serve five secondary substations (Sec SS), Figure 1. Each of the Sec SSs supplies the electricity demanded by the buildings next to it. The Sec SS 1 has an auxiliary connection, which allows partial supply to the hospital in case of failure of the main connection. 


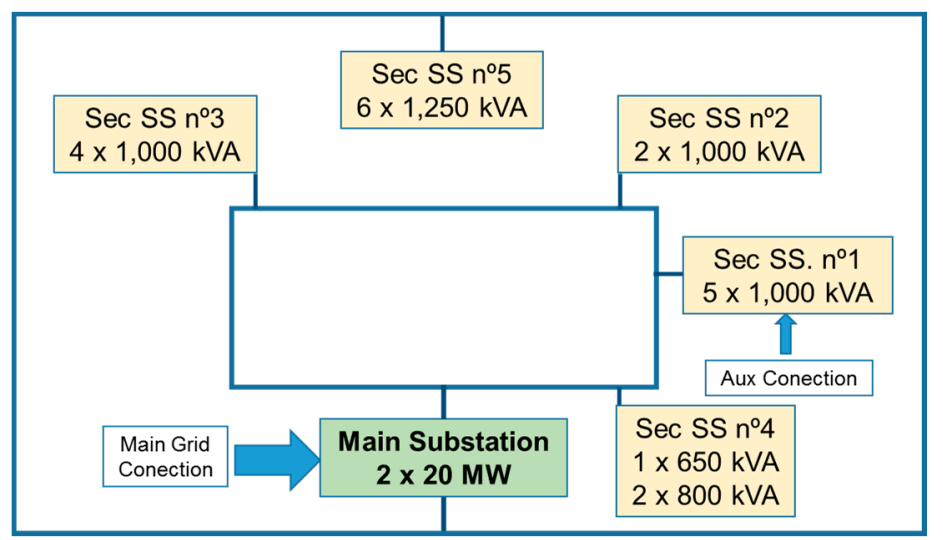

Figure 1. Schematic of the main substation and Sec SSs of the Hospital.

\subsubsection{Energy Demand from the Hospital}

The energy demand of the hospital is mainly provided to service (1) lighting; (2) elevators; (3) medical equipment; (4) the hospital services such as: water pumping, compressed air, air conditioning, ventilation, etc.; (5) medicine and food cold stores; and (6) small appliances such as coffee makers, televisions, microwaves, or soft drink machines.

In this paper, the energy demand in this hospital in the last 5 years has been studied. The average energy consumed annually was $19.6 \mathrm{GWh}$. Figure 2 shows the monthly demand and the percentage that this represents on the annual demand. Sec SS 5 corresponds to a building recently put into operation, so there is no previous data, and this Sec SS has been left out of the study presented in this work.

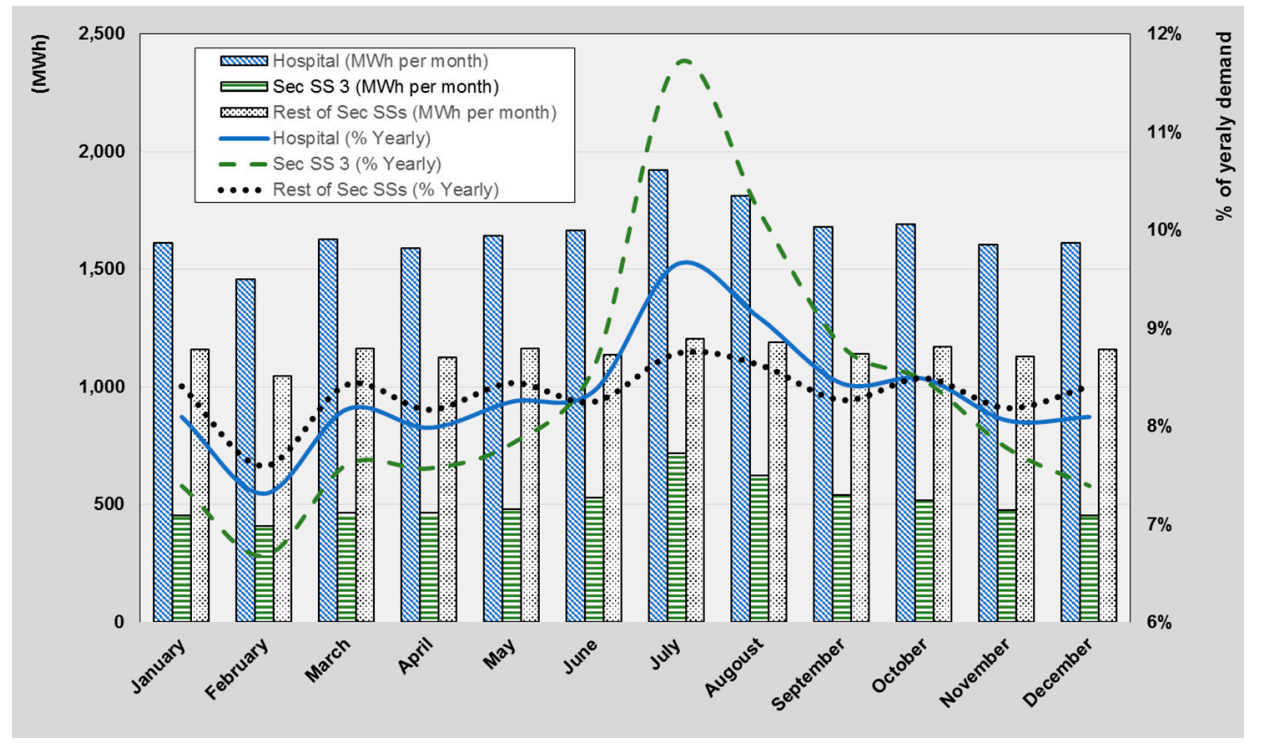

Figure 2. Monthly electricity demand in the hospital and percentage of monthly demand over the annual: Hospital, Sec SS 3 and Rest of Sec SSs (1, 2 and 4).

The future growth of the hospital would modify its consumption, and therefore the amount of electricity transformed in the MAIN Substation (Figure 1). However, the Sec SS 3 will be still feeding the same loads, and there will be no change in its operation.

From the analysis of the data, it has been observed that in the Sec SS 3 there is a large variation of the monthly demand, with respect to the other three Sec SSs. The reason is that this Sec SS supplies 
electricity to the building in which the central air conditioning are housed, so the electricity demand for this service is supplied from this Sec SS to the entire hospital. This effect can be observed in Figure 2, in which the hospital demand has been disaggregated in the Sec SS 3 and the rest of Sec SSs (1,2 and 4). Thus, the next section will focus on the Sec SS 3.

\subsubsection{Secondary Substation Studied}

The study proposed does not make sense when demand is constant, since in that case there are always a number of connected transformers that optimizes efficiency. Analogously, it also makes no sense if the Sec SS has a single transformer, since in that case there is only one connection option. Therefore, this type of study offers greater possibilities of energy saving with: (1) more variations, both daily and seasonal, in the demand of the Sec SS; and (2) a greater number of transformers that can enter into service. In the studied hospital complex, this occurs in the Sec SS 3. The magnitude of the changes in demand is basically based on the fact that this Sec SS is connected to the central air conditioning services of the hospital, which implies that there are large variations in both hourly and seasonal demand. The variation in hourly demand is also associated with the fact that this Sec SS also provides the consumption of the hot water pumping service of the hospital, and lighting, elevators, medical equipment, etc. of nearby buildings. The differences of hourly consumption, in a same day, can cause that the demand in the hour of greater consumption multiplies by 2.5 the demand of the hour of lower consumption. Regarding the differences in monthly consumption, the demand corresponding to the month of greatest consumption reaches $175 \%$ of the energy supplied in the month of least consumption.

Analyzing the demand of the Sec SS 3, it has been observed that there is a great difference in the demand between the one that takes place in working days and the one on holidays. This is basically due to the existence of consultations and diagnostic services in the hospital, which only operate on weekdays and therefore do not require space heating or air conditioning (supplied from Sec SS 3). Figure 3 shows the monthly and daily energy demands corresponding to the Sec SS 3. This has been carried out by differentiating between working and non-working days.

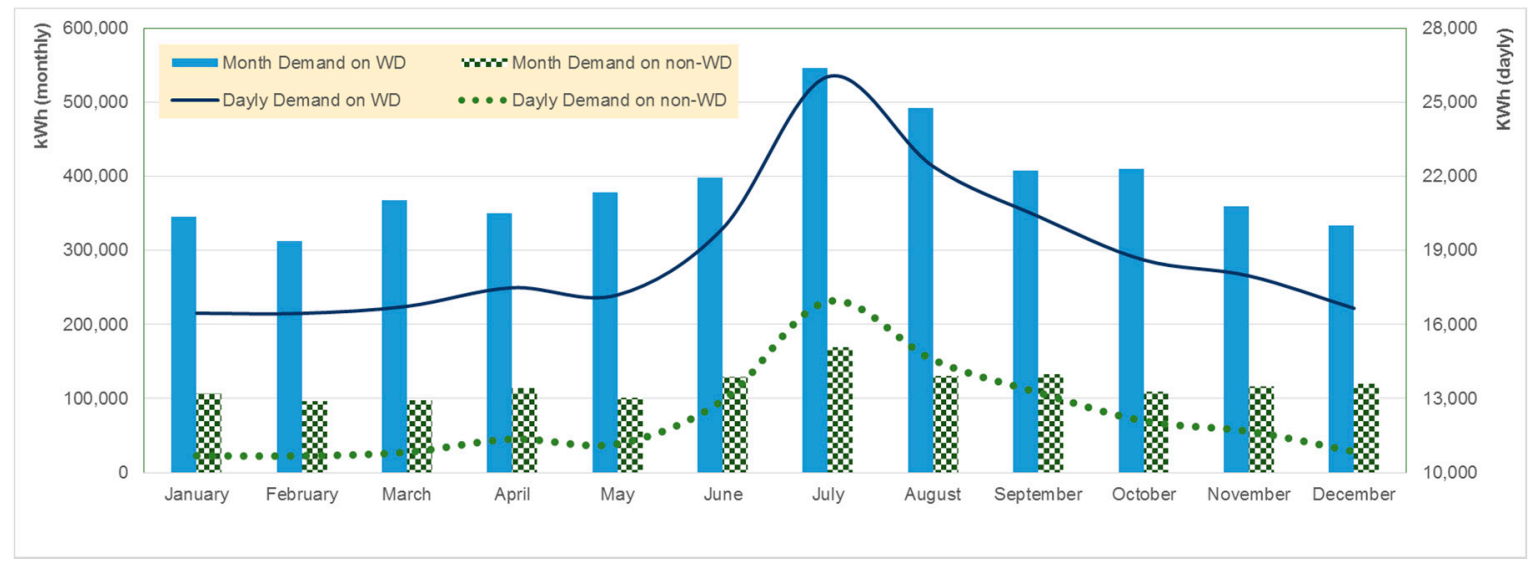

Figure 3. Monthly and daily demands performed on the Sec SS 3.

The total demand for the last spring month, June, is higher than total demand of the first spring month, April. However, there are not significant differences in the time distribution in which this demand is performed. Considering the daily demand, it has been observed that there are three annual periods in which the hourly percentages of daily demand are similar. These periods relate to the different climatology, and correspond to: winter (16 December to 15 March), spring-autumn (16 March to 15 June and 16 September to 15 December) and summer (16 June to 15 September). 
Figure 4 shows the values of the hourly demand percentages with respect to the daily demand in the Sec SS 3. This has been carried out for all three periods of time, considering whether it is a working or non-working day. It is observed that the demand in the non-working days is much more constant than in the working days; this is mainly due to the operation of consultation and diagnostic services.

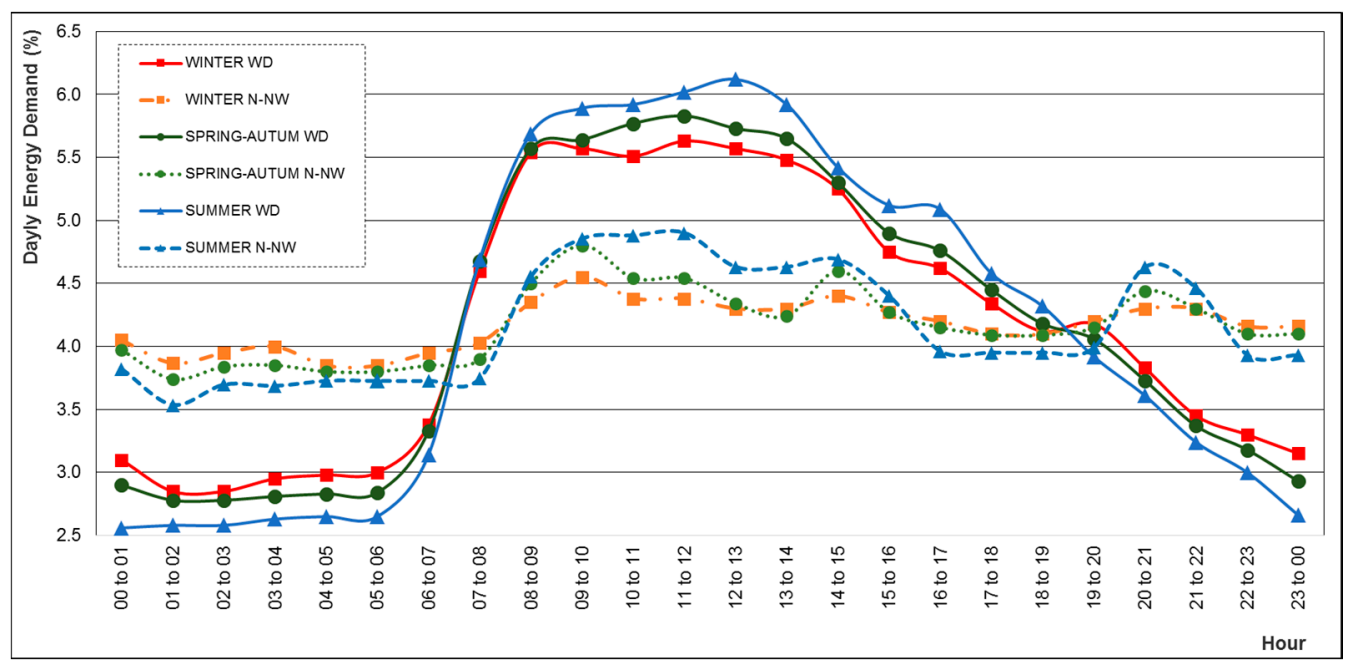

Figure 4. Percentage of daily demand in the Sec SS 3.

The Sec SS 3 has installed 4 dry transformers of $1000 \mathrm{kVA}$ each. In their current use, three remain always connected, the forth being in reserve, to be able to serve the hospital in case of failure of one of the other three. According to the data supplied by the manufacturer [20], its short-circuit and no-load power values are: $P_{S C}=9.79 \mathrm{~kW}$ and $P_{0}=2.3 \mathrm{~kW}$. Considering these data, and according to Equation (6), the optimum load index and the maximum efficiency will be: $C_{\text {opt }}=0.4847$ and $\eta_{\max }=0.99060$.

In Figure 5 the efficiency of the Sec SS 3 is shown, taking into account the connection of 1, 2, 3 or 4 transformers, depending on the power demanded, $P_{2}$. This efficiency has been calculated according to Equation (6). The figure shows that for each power there are a number of transformers that optimize the efficiency of the Sec SS 3.

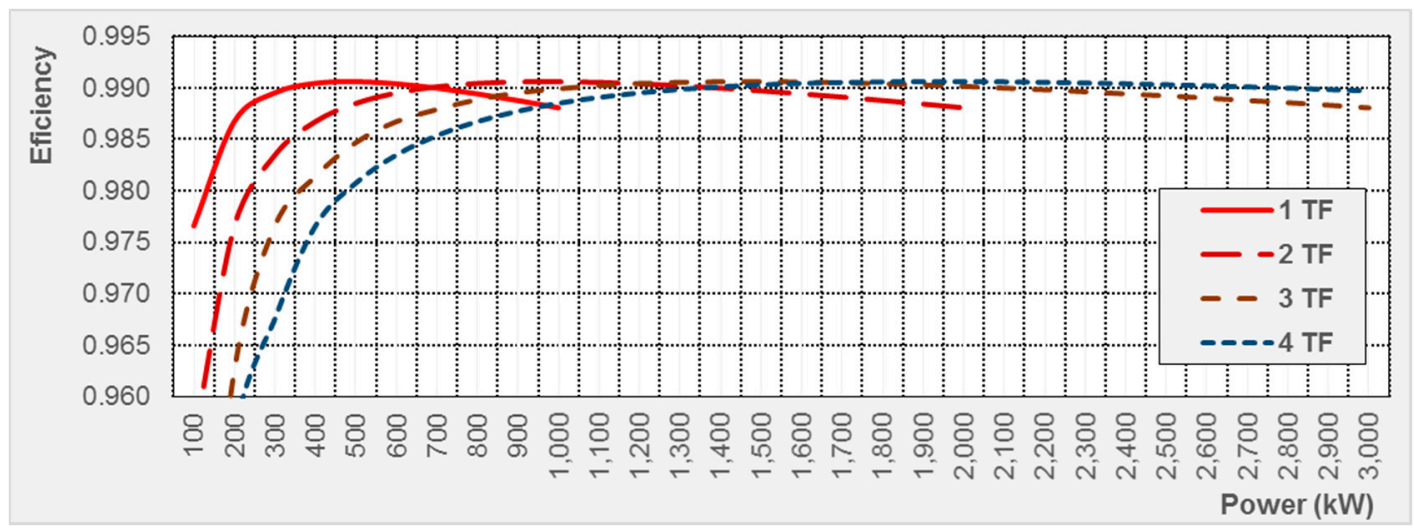

Figure 5. Efficiency of the Sec SS 3 depending on demand and number transformers (TF) connected.

As can be seen in Figure 5, the connection of the third transformer is carried out at powers around $1300 \mathrm{~kW}$, which is $65 \%$ of the power corresponding to the connection of two transformers $(2 \times 1000 \mathrm{~kW}) .1300 \mathrm{~kW}$ is $43 \%$ of the power of three parallel transformers $(3 \times 1000 \mathrm{~kW})$. In the disconnection maneuver, the opposite would happen, when the third transformer would be removed, the load of the two remaining transformers will be $65 \%$. 
The optimum load of the transformers is around $45 \%$, and the connection of a second or a third transformer is carried out at powers far from the maximum load of the transformer, Figure 5, so there would be no risk for reliability of electrical power delivery. In addition, the reserve transformer of the Sec SS 3 is ready to automatically connect in case it is necessary.

\section{Results}

Table 4 shows, for the existing transformers, the number of machines that must be connected in each time period so that losses are as small as possible. The same number is given in Table 5 , but the number of connected machines is selected for each work shift ( $23 \mathrm{~h}$ to $7 \mathrm{~h}, 7 \mathrm{~h}$ to $15 \mathrm{~h}$ and $15 \mathrm{~h}$ to $23 \mathrm{~h}$ ). The numbers that appear in both tables refer to working days and non-working days. The hours in which an on/off maneuver must be performed are shown in shaded text.

Table 4. Number of connected transformers that minimize losses on Sec SS 3 (WD/non-WD).

\begin{tabular}{|c|c|c|c|c|c|c|c|c|c|c|c|c|c|c|c|c|}
\hline$\frac{\text { Season }}{\text { Month }}$ & \multicolumn{3}{|c|}{ Winter } & \multicolumn{5}{|c|}{ Spring } & \multicolumn{3}{|c|}{ Summer } & \multicolumn{4}{|c|}{ Autum } & $\begin{array}{r}\text { Winter } \\
\text { Dec. }\end{array}$ \\
\hline 01 to 02 & $1 / 1$ & $1 / 1$ & $1 / 1$ & $1 / 1$ & $1 / 1$ & $1 / 1$ & $1 / 1$ & $1 / 1$ & $1 / 1$ & $1 / 1$ & $1 / 1$ & $1 / 1$ & $1 / 1$ & $1 / 1$ & $1 / 1$ & $1 / 1$ \\
\hline 02 to 03 & $1 / 1$ & $1 / 1$ & $1 / 1$ & $1 / 1$ & $1 / 1$ & $1 / 1$ & $1 / 1$ & $1 / 1$ & $1 / 1$ & $1 / 1$ & $1 / 1$ & $1 / 1$ & $1 / 1$ & $1 / 1$ & $1 / 1$ & $1 / 1$ \\
\hline 03 to 04 & $1 / 1$ & $1 / 1$ & $1 / 1$ & $1 / 1$ & $1 / 1$ & $1 / 1$ & $1 / 1$ & $1 / 1$ & $1 / 1$ & $1 / 1$ & $1 / 1$ & $1 / 1$ & $1 / 1$ & $1 / 1$ & $1 / 1$ & $1 / 1$ \\
\hline 06 to 07 & $1 / 1$ & $1 / 1$ & $1 / 1$ & $1 / 1$ & $1 / 1$ & $1 / 1$ & $1 / 1$ & $2 / 1$ & $2 / 1$ & $2 / 1$ & $2 / 1$ & $1 / 1$ & $1 / 1$ & $1 / 1$ & $1 / 1$ & $1 / 1$ \\
\hline 07 to 08 & $2 / 1$ & $2 / 1$ & $2 / 1$ & $2 / 1$ & $2 / 1$ & $2 / 1$ & $2 / 1$ & $2 / 1$ & $3 / 1$ & $2 / 1$ & $2 / 1$ & $2 / 1$ & $2 / 1$ & $2 / 1$ & $2 / 1$ & $2 / 1$ \\
\hline 08 to 09 & $2 / 1$ & $2 / 1$ & $2 / 1$ & $2 / 1$ & $2 / 1$ & $2 / 1$ & $2 / 1$ & $3 / 2$ & $3 / 2$ & $3 / 1$ & $3 / 2$ & $2 / 1$ & $2 / 1$ & $2 / 1$ & $2 / 1$ & $2 / 1$ \\
\hline 09 to 10 & $2 / 1$ & $2 / 1$ & $2 / 1$ & $2 / 1$ & $2 / 1$ & $2 / 1$ & $2 / 1$ & $3 / 2$ & $3 / 2$ & $3 / 2$ & $3 / 2$ & $2 / 1$ & $2 / 1$ & $2 / 1$ & $2 / 1$ & $2 / 1$ \\
\hline 10 to 11 & $2 / 1$ & $2 / 1$ & $2 / 1$ & $2 / 1$ & $2 / 1$ & $2 / 1$ & $2 / 1$ & $3 / 2$ & $3 / 2$ & $3 / 2$ & $3 / 2$ & $2 / 1$ & $2 / 1$ & $2 / 1$ & $2 / 1$ & $2 / 1$ \\
\hline 15 to 16 & $2 / 1$ & $2 / 1$ & $2 / 1$ & $2 / 1$ & $2 / 1$ & $2 / 1$ & $2 / 1$ & $3 / 1$ & $3 / 2$ & $2 / 1$ & $3 / 2$ & $2 / 1$ & $2 / 1$ & $2 / 1$ & $2 / 1$ & $2 / 1$ \\
\hline 16 to 17 & $2 / 1$ & $2 / 1$ & $2 / 1$ & $2 / 1$ & $2 / 1$ & $2 / 1$ & $2 / 1$ & $3 / 1$ & $3 / 2$ & $2 / 1$ & $3 / 1$ & $2 / 1$ & $2 / 1$ & $2 / 1$ & $2 / 1$ & $2 / 1$ \\
\hline 17 to 18 & $2 / 1$ & $2 / 1$ & $2 / 1$ & $2 / 1$ & $2 / 1$ & $2 / 1$ & $2 / 1$ & $2 / 1$ & $2 / 1$ & $2 / 1$ & $2 / 1$ & $2 / 1$ & $2 / 1$ & $2 / 1$ & $2 / 1$ & $1 / 1$ \\
\hline 18 to 19 & $1 / 1$ & $2 / 1$ & $1 / 1$ & $2 / 1$ & $2 / 1$ & $2 / 1$ & $2 / 1$ & $2 / 1$ & $2 / 1$ & $2 / 1$ & $2 / 1$ & $2 / 1$ & $2 / 1$ & $2 / 1$ & $2 / 1$ & $1 / 1$ \\
\hline 19 to 20 & $1 / 1$ & $2 / 1$ & $1 / 1$ & $1 / 1$ & $2 / 1$ & $1 / 1$ & $1 / 1$ & $2 / 1$ & $2 / 1$ & $2 / 1$ & $2 / 1$ & $1 / 1$ & $2 / 1$ & $2 / 1$ & $2 / 1$ & $1 / 1$ \\
\hline 20 to 21 & $1 / 1$ & $1 / 1$ & $1 / 1$ & $1 / 1$ & $1 / 1$ & $1 / 1$ & $1 / 1$ & $2 / 2$ & $2 / 2$ & $2 / 1$ & $2 / 2$ & $1 / 1$ & $1 / 1$ & $1 / 1$ & $1 / 1$ & $1 / 1$ \\
\hline 21 to 22 & $1 / 1$ & $1 / 1$ & $1 / 1$ & $1 / 1$ & $1 / 1$ & $1 / 1$ & $1 / 1$ & $2 / 2$ & $2 / 2$ & $2 / 1$ & $2 / 2$ & $1 / 1$ & $1 / 1$ & $1 / 1$ & $1 / 1$ & $1 / 1$ \\
\hline 22 to 23 & $1 / 1$ & $1 / 1$ & $1 / 1$ & $1 / 1$ & $1 / 1$ & $1 / 1$ & $1 / 1$ & $2 / 1$ & $2 / 1$ & $1 / 1$ & $2 / 1$ & $1 / 1$ & $1 / 1$ & $1 / 1$ & $1 / 1$ & $1 / 1$ \\
\hline 23 to 00 & $1 / 1$ & $1 / 1$ & $1 / 1$ & $1 / 1$ & $1 / 1$ & $1 / 1$ & $1 / 1$ & $1 / 1$ & $1 / 1$ & $1 / 1$ & $1 / 1$ & $1 / 1$ & $1 / 1$ & $1 / 1$ & $1 / 1$ & $1 / 1$ \\
\hline
\end{tabular}

Table 5. Number of connected transformers that minimize losses on Sec SS 3 at each shift (WD/non-WD).

\begin{tabular}{|c|c|c|c|c|c|c|c|c|c|c|c|c|c|c|c|c|}
\hline \multirow{2}{*}{$\underbrace{\text { Season }}_{\text {Hour }}$} & \multicolumn{3}{|c|}{ Winter } & \multicolumn{4}{|c|}{ Spring } & \multicolumn{4}{|c|}{ Summer } & \multicolumn{4}{|c|}{ Autum } & \multirow{2}{*}{$\begin{array}{r}\text { Winter } \\
\text { Dec. }\end{array}$} \\
\hline & Jan. & Feb. & Mar. & Mar. & Apr. & May & Jun. & Jun. & Jul. & Aug. & Sep. & Sep. & Oct. & Nov. & Dec. & \\
\hline 23 to 07 & $1 / 1$ & $1 / 1$ & $1 / 1$ & $1 / 1$ & $1 / 1$ & $1 / 1$ & $1 / 1$ & $1 / 1$ & $1 / 1$ & $1 / 1$ & $1 / 1$ & $1 / 1$ & $1 / 1$ & $1 / 1$ & $1 / 1$ & $1 / 1$ \\
\hline 07 to 15 & $2 / 1$ & $2 / 1$ & $2 / 1$ & $2 / 1$ & $2 / 1$ & $2 / 1$ & $2 / 1$ & $3 / 2$ & $3 / 2$ & $3 / 1$ & $3 / 2$ & $2 / 1$ & $2 / 1$ & $2 / 1$ & $2 / 1$ & $2 / 1$ \\
\hline 15 to 23 & $1 / 1$ & $2 / 1$ & $1 / 1$ & $2 / 1$ & $2 / 1$ & $2 / 1$ & $2 / 1$ & $2 / 1$ & $2 / 1$ & $2 / 1$ & $2 / 1$ & $2 / 1$ & $2 / 1$ & $2 / 1$ & $2 / 1$ & $1 / 1$ \\
\hline
\end{tabular}

In Table 4, it can be seen that the best time to perform the connection maneuvers in the morning can vary between 6 a.m. and 8 a.m., depending on the month of the year. In the afternoon and evening, the distribution of the optimal connection periods has much greater variation. Comparing Tables 4 and 5 , it can be observed that making the connections at the beginning of the work shifts simplifies the management of the substation.

Figure 6 shows the monthly losses with the three control systems: three permanently connected transformers, the number of transformers in operation is fixed at the start of each work shift, and hourly control of the optimal number of connected transformers. For the three annual periods and considering 
working days and non-working days, Table 6 presents the percentages of losses of the two alternative control systems, the permanent connection of three transformers being considered as the reference case.

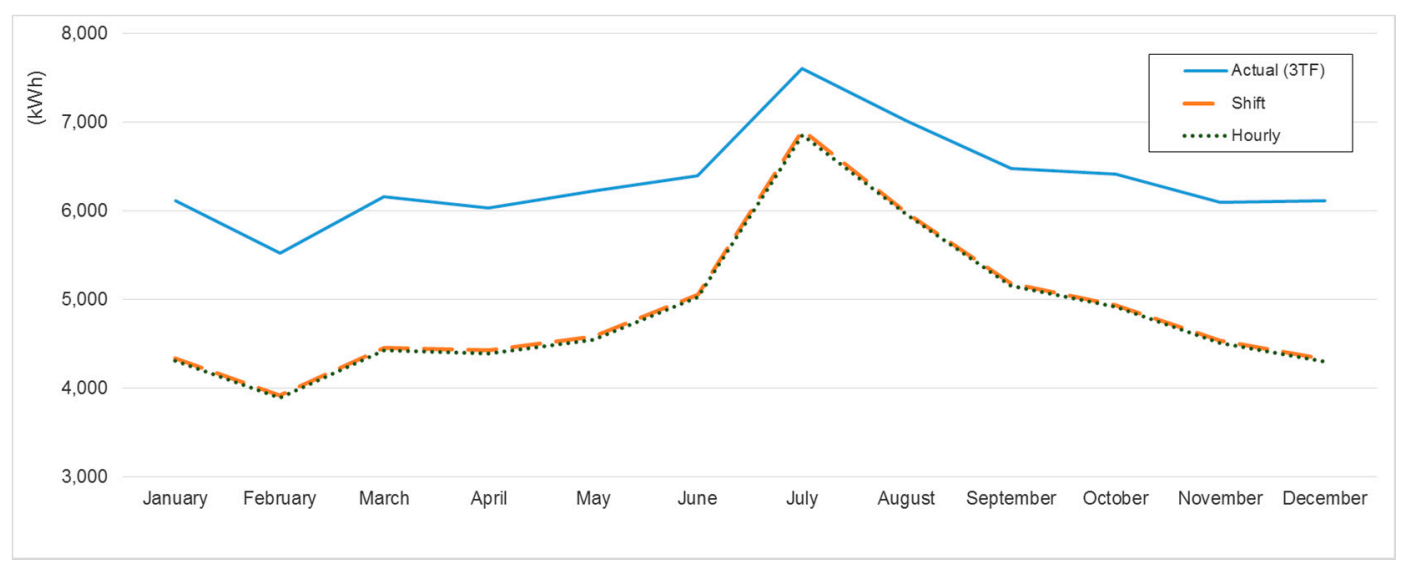

Figure 6. Monthly energy losses on Sec SS 3 with the three control systems for the number of connected transformers.

Table 6. Percentage of losses on Sec SS 3 with respect to the permanent connection of three transformers (\%).

\begin{tabular}{|c|c|c|c|c|c|c|c|c|c|}
\hline \multirow{2}{*}{$\begin{array}{c}\text { Season } \\
\text { Scenario }\end{array}$} & \multicolumn{2}{|c|}{ Winter } & \multicolumn{2}{|c|}{ Spring/Autumn } & \multicolumn{2}{|c|}{ Summer } & \multicolumn{2}{|c|}{ TOTAL } & \multirow{2}{*}{ TOTAL } \\
\hline & WD & Non-WD & WD & Non-WD & WD & Non-WD & WD & Non-WD & \\
\hline Actual (3TF) & 100 & 100 & 100 & 100 & 100 & 100 & 100 & 100 & 100 \\
\hline Work shift TF & 77.1 & 55.2 & 79.9 & 58.3 & 91.8 & 77.1 & 82.7 & 62.5 & 77.0 \\
\hline Ideal & 76.5 & 55.2 & 79.9 & 58.3 & 91.4 & 76.5 & 82.1 & 62.4 & 76.5 \\
\hline
\end{tabular}

From having three transformers permanently connected to controlling their number, it is possible to obtain a significant loss reduction. In this Sec SS 3, losses can be reduced by $23.5 \%$. With respect to the two proposed systems, when connecting a specific number of transformers in each work shift, the variation in the reduction of losses barely reaches $0.5 \%$, with no significant difference being observed in monthly losses or between working days and non-working days.

On non-working days there is a greater loss reduction than on working days. This is because on non-working days there is less demand for electricity, and reducing to one the number of connected transformers produces the greatest increase in the efficiency.

The monthly losses are shown in Figures 7 and 8 for the three transformers connection systems, however, in this case the replacement of the transformers by higher efficiency machines that comply with TIER1 and TIER2, has been considered. Table 7 shows the percentages of losses of the three alternative control systems, taking into account the three annual periods, working and non-working days. 


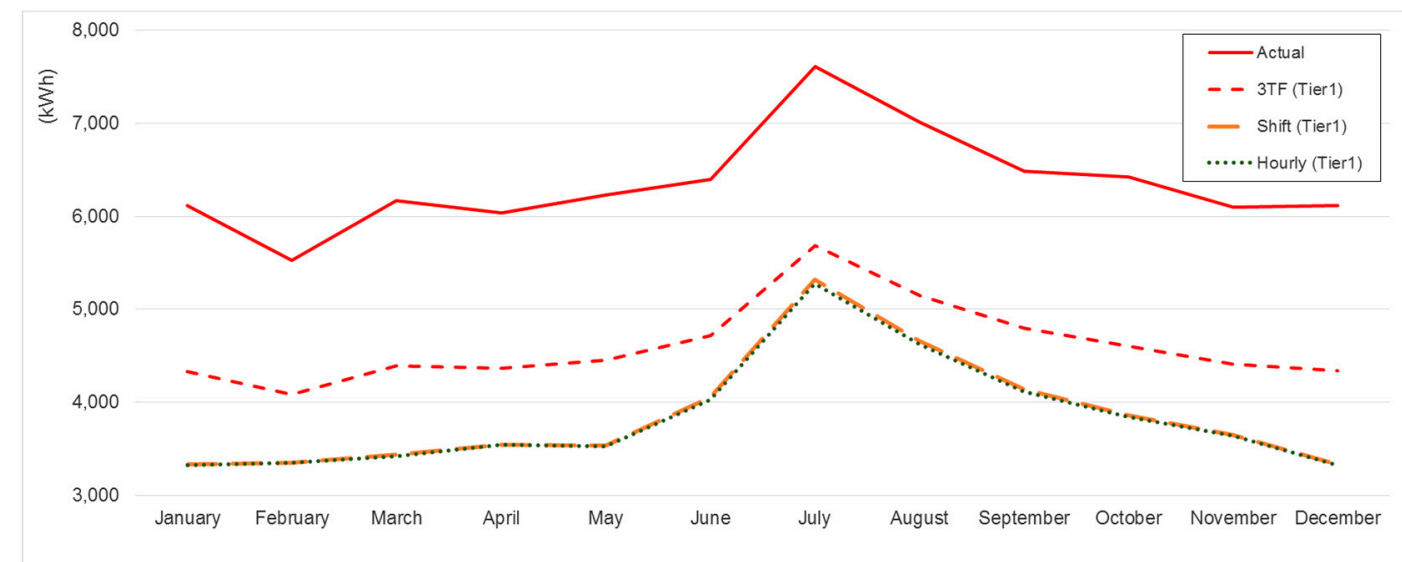

Figure 7. Monthly energy losses on Sec SS 3 with the three control systems of the number of transformers connected, considering that transformers fulfilled TIER1.

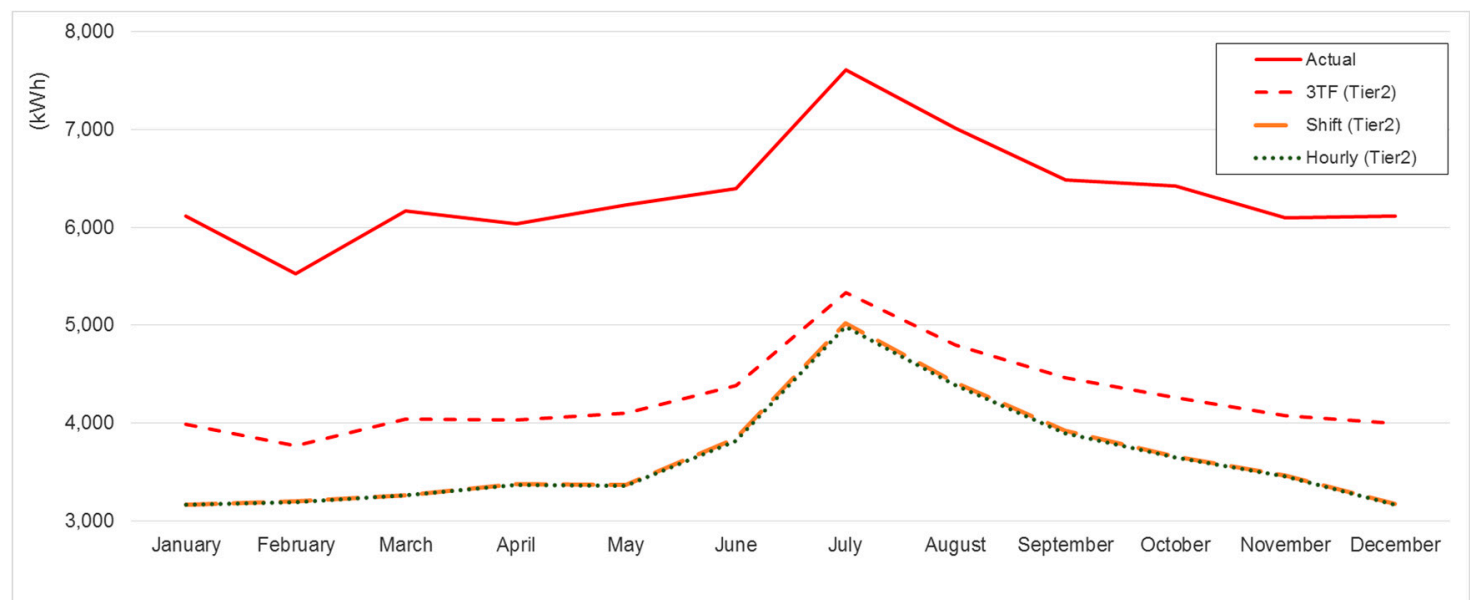

Figure 8. Monthly energy losses on Sec SS 3 with the three control systems of the number of transformers connected, considering that transformers fulfilled TIER2.

Table 7. Percentage of losses with new transformers compared to the current connection (\%).

\begin{tabular}{ccccccccccc}
\hline \multicolumn{2}{c}{ Season } & \multicolumn{2}{c}{ Winter } & \multicolumn{2}{c}{ Spring/Autumn } & \multicolumn{2}{c}{ Summer } & \multicolumn{2}{c}{ TOTAL } & \multirow{2}{*}{ TOTAL } \\
\cline { 1 - 10 } TIER & Scenario & WD & Non-WD & WD & Non-WD & WD & Non-WD & WD & Non-WD & \\
\hline \multirow{2}{*}{ TIER1 } & 3TF & 72.8 & 69.7 & 72.7 & 70.0 & 75.6 & 71.6 & 73.5 & 70.4 & 72.6 \\
& Shift & 61.4 & 44.1 & 62.8 & 46.2 & 72.2 & 60.0 & 65.2 & 49.4 & 60.7 \\
& Hourly & 61.3 & 44.1 & 62.6 & 46.2 & 71.4 & 59.8 & 64.8 & 49.3 & 60.4 \\
\hline \multirow{4}{*}{ TIER2 } & 3TF & 67.3 & 63.6 & 67.4 & 63.9 & 71.1 & 66.0 & 68.5 & 64.4 & 67.3 \\
& Shift & 58.4 & 42.1 & 59.7 & 44.2 & 68.2 & 56.5 & 61.9 & 47.0 & 57.6 \\
& Hourly & 58.2 & 42.1 & 59.5 & 44.2 & 67.6 & 56.5 & 61.6 & 46.9 & 57.4 \\
\hline
\end{tabular}

From the previous results, it is observed that the substitution of the current transformers by others that comply with the TIER1 and TIER2 regulations would produce a reduction of the current losses of $27.4 \%$ and $32.7 \%$, respectively. If this substitution were combined with the control strategy, the losses could be reduced by $39.6 \%$ and $42.6 \%$, respectively. The control strategy would continue to achieve energy savings, but as the nominal efficiency of the transformers improves, the influence of the control strategy becomes less important. The greatest loss reduction achieved by the control strategy is still achieved on non-working days. 


\section{Conclusions}

This work has proposed a methodology to optimize the efficiency of a secondary substation, in which several transformers are installed in parallel. The electrical demand in this point of the network suffers both daily and seasonal variations. The method is based on selecting, according to the energy demand, the number of transformers that must be connected every hour. This is carried out by making the transformers work near their maximum efficiency point, and thereby minimizing energy losses.

This methodology has been applied to a secondary substation located in a hospital center. In this substation there are three transformers permanently connected and another one in reserve. Regarding the demand of electricity, the daily and seasonal variation has been taken into account, as well as the variation between working days and holidays. The results have shown that choosing the number of connected transformers improves the efficiency of the substation compared to traditional operation, in which there is a fixed number of machines running in parallel.

The savings have also been determined considering that the connection/disconnection operations of transformers are carried out at the beginning of the work shifts and not each hour. This solution reduces the number of maneuvers to be carried out and facilitates its application. In this installation, there are hardly significant differences between these two options, since similar energy savings are achieved. However, in other facilities it would be possible to obtain different results.

On the other hand, knowing the number of connected transformers that optimizes the efficiency in each time period, would allow for the programming of the maintenance of the facility. This could be carried out in the periods of time in which a transformer is disconnected. Therefore, the maintenance would not affect the substation efficiency.

In the case studied, an annual reduction of $23 \%$ on secondary substation losses could be obtained, when considering the work shift maneuvers. This work has also studied the installation of new transformers fulfilling the European Regulation 548/2014. The results show that significant savings will be also reached, being $17 \%$ and $14 \%$ in the case of complying with TIER 1 and TIER 2 levels, respectively. This implies that if the transformers are replaced by others with better efficiency, the proposed method would continue to produce energy savings, but the percentage would be lower.

Author Contributions: C.J.R., A.S. and F.O. conceived and designed the research framework; C.J.R., C.O. and A.O. analyzed the data and wrote the paper.

Conflicts of Interest: The authors declare no conflict of interest.

\section{Nomenclature}

$\begin{array}{ll}C & \text { load index }(0 \text { to } 1) \\ C_{\text {opt }} & \text { optimum load index } \\ P_{L} & \text { transformer power losses, } \mathrm{W} \\ P_{0} & \text { transformer no load losses, } \mathrm{W} \\ P_{k} & \text { transformer load losses, } \mathrm{W} \\ P_{s c} & \text { transformer short circuit losses, } \mathrm{W} \\ P_{1} & \text { transformer input power, } \mathrm{W} \\ P_{2} & \text { transformer output power, } \mathrm{W} \\ \text { Sec SS } & \text { secondary substation } \\ S_{2} & \text { transformer output apparent power, VA } \\ S_{n} & \text { transformer nominal output apparent power, VA } \\ \eta & \text { transformer efficiency (0 to 1) } \\ \eta_{\max } & \text { transformer maximum efficiency } \\ \cos \varphi_{2} & \text { load power factor }\end{array}$




\section{References}

1. IDAE, Institute for Diversification and Energy Saving, Spanish Ministry of Energy. Available online: http:/ / sieeweb.idae.es/ consumofinal/default.asp (accessed on 27 December 2017).

2. REE, Red Eléctrica Española. Available online: http:/ / www.ree.es/es/estadisticas-del-sistema-electricoespanol/informe-anual/informe-del-sistema-electrico-espanol-2016 (accessed on 27 December 2017).

3. Pezzini, P.; Gomis-Bellmunt, O.; Frau-Valentí, J.; Sudrià-Andreu, A. Energy efficiency optimization in distribution transformers considering Spanish distribution regulation policy. Energy 2010, 35, 4685-4690. [CrossRef]

4. Georgilakis, P.S. Environmental cost of distribution transformer losses. Appl. Energy 2011, 88, 3146-3155. [CrossRef]

5. Targosz, R.; Fassbinder, S.; Baggini, A. Electrical Energy Efficiency: Technologies and Applications; Sumper, A., Baggini, A., Eds.; Power Transformers; John Wiley \& Sons, Ltd.: Chichester, UK, 2012; pp. 21-69, ISBN 9780470975510.

6. IEEE Std C57.120 ${ }^{\mathrm{TM}}$-2017. IEEE Guide for Loss Evaluation of Distribution and Power Transformers and Reactors; IEEE: New York, NY, USA, 2017.

7. Olivares-Galván, J.C.; Georgilakis, P.S.; Ocon-Valdez, R. A Review of Transformer Losses. Electr. Power Compon. Syst. 2009, 37, 1046-1062. [CrossRef]

8. Olivares, J.C.; Liu, Y.; Cañedo, J.M.; Escarela-Pérez, R.; Driesen, J.; Moreno, P. Reducing Losses in Distribution Transformers. IEEE Trans. Power Deliv. 2003, 18, 821-826. [CrossRef]

9. Alves, F.; Lebourgeois, R.; Waeckerlé, T. Soft magnetic materials for electrical engineering: State of the art and recent advances. Eur. Trans. Electr. Power 2005, 15, 467-479. [CrossRef]

10. Tanzer, T.; Pregartner, H.; Riedenbauer, M.; Labinsky, R.; Witlatschil, M.; Muetze, A.; Krischan, K. Magnetic Properties and Their Relation to the No-Load Noise and No-Load Losses of Large Power Transformers. In Proceedings of the 2017 IEEE International Electric Machines and Drives Conference (IEMDC), Miami, FL, USA, 21-24 May 2017.

11. Magdaleno-Adame, S.; Melgoza-Vazquez, E.; Olivares-Galvan, J.C.; Escarela-Perez, R. Loss reduction by combining electrical steels in the core of power transformers. Int. Trans. Electr. Energy Syst. 2016, 26, 1737-1751. [CrossRef]

12. Freitag, C.; Leibfried, T. Mixed core design for power transformers to reduce core losses. In Proceedings of the 2017 International Conference on Optimization of Electrical and Electronic Equipment (OPTIM) and 2017 Intl Aegean Conference on Electrical Machines and Power Electronics (ACEMP), Brasov, Romania, 25-27 May 2017.

13. Xu, Y.; Dong, Z.Y.; Wong, K.P.; Liu, E.; Yue, B. Optimal Capacitor Placement to Distribution Transformers for Power Loss Reduction in Radial Distribution Systems. IEEE Trans. Power Syst. 2013, 28, 4072-4079. [CrossRef]

14. Borge-Diez, D.; Colmenar-Santos, A.; Castro-Gil, M.; Carpio-Ibáñez, J. Parallel distribution transformer loss reductions: A proposed method and experimental validation. Electr. Power Energy Syst. 2013, 49, 170-180. [CrossRef]

15. Wolde-Ghiorgis, W.; Bekele, W. A Simulation Study of EEPCo's Medium Voltage Distribution Feeders for Technical Power Loss Reductions: A Case Study of Technical Power Losses in the Outgoing Feeders from Sebeta Substation. In Proceedings of the IEEE AFRICON Conference, Addis Ababa, Ethiopia, 14-17 September 2015.

16. Biryulin, V.I.; Gorlov, A.N.; Larin, O.M.; Kudelina, D.V. Calculation of Power Losses in the Transformer Substation. In Proceedings of the 2016 13th International Scientific-Technical Conference on Actual Problems of Electronics Instrument Engineering (APEIE), Novosibirsk, Russia, 3-6 October 2016.

17. Ortiz-Fernández, F.; Renedo-Estébanez, C.J.; Delgado-San-Román, F.; Ortiz-Fernández, A.; Fernández-Diego, I.; Olmo-Salas, C. Effect of the acquisition, considering the capitalization of losses, in fleet efficiency of power transformers. DYNA 2016, 91, 564-570.

18. The European Commission. Commission Regulation (EU) No 548/2014 of 21 May 2014 on implementing Directive 2009/125/EC of the European Parliament and of the Council with regard to small, medium and large power transformers. Off. J. Eur. Union 2014, L152, 1-15. 
19. American Society of Heating, Refrigerating and Air-Conditioning Engineers (ASHRAE). Advanced Energy Design Guide for Large Hospitals; ASHRAE: Atlanta, GA, USA, 2012; ISBN 978-1-936504-23-7. Available online: https: / / www.ashrae.org/standards-research--technology /advanced-energy-design-guides /50percent-aedg-free-download (accessed on 27 December 2017).

20. Asea Brown Boveri, Ltd. Vacuum Cast Coil Dry Type Distribution Transformers. Available online: http:/ / www04.abb.com/global/seitp/seitp202.nsf/0/1a97c23d16c6212ec1257673004c67ca/\$file/ Vacuum+cast+coil+dry+type+distribution+transformers.pdf (accessed on 17 December 2017).

C 2018 by the authors. Licensee MDPI, Basel, Switzerland. This article is an open access article distributed under the terms and conditions of the Creative Commons Attribution (CC BY) license (http:/ / creativecommons.org/licenses/by/4.0/). 